\title{
OPERATOR EFFORT ON THE OPERATION OF THE KNAPSACK SPRAYER PUMPING LEVER
}

\author{
Edson Lambrecht ${ }^{1 *}$, Douglas S. da Rosa ${ }^{2}$, Roberto L. T. Machado ${ }^{2}$, \\ Antônio L. T. Machado ${ }^{2}$, Ângelo V. dos Reis ${ }^{2}$
}

${ }^{1 *}$ Corresponding author. Universidade Federal de Pelotas/ Pelotas - RS, Brasil. E-mail: edsonlambrecht@g mail.com

\section{KEYWORDS}

Ergonomics, upper limb effort, effort in sprayers.

\begin{abstract}
Several equipments are used in the application of agrochemicals by small scale farmers, with emphasis on the knapsack hand sprayer due to the low cost of acquisition and viability of use in different operating conditions. Although it is an equipment widely used, few studies have been developed in order to ascertain its functional characteristics. This study has the objective of presenting a methodology to measure the effort to which the operator is subjected in the activation of the pumping lever of knapsack hand sprayer verifying if these machines fit within the limitations foreseen by the Brazilian laws and international regulations. The methodology used was adequate to measure the operator's required efforts for the activation of knapsack hand sprayer. All sprayers tested with water have achieved satisfactory results by national standards, but only two by international regulations.
\end{abstract}

\section{INTRODUCTION}

The applications of pesticides are made by means of spraying, that is, by the generation and emission of liquid particles, in order to control pests and help to increase the productivity of the crops, being part of the world agricultural production (Silva et al., 2015).

Several equipments are used in the application of agrochemicals, and in the family properties the knapsack hand sprayer is highlighted due to the low cost of acquisition and variability of use in different operating conditions (Lopes et al., 2011) and technologies, as it can incorporate even the electrostatic charging of the spray liquid (Mamidi et al., 2013).

The standard ISO 19932-1: 2013 (Crop Protection Equipment - Knapsack sprayer Part 1: Requirements and test methods) specifies the minimum requirements, test methods and performance limits for the knapsack sprayer in order to ensure safety.

According to Souza \& Santana (2011) workers, when using heavy equipment are subject to fatigue and development of musculoskeletal problems. The authors recommend the adoption of posture training, workout gymnastics and the adoption of scheduled breaks to mitigate the risks involved due to the sprayer weight. This recommendation is hardly followed by the users of knapsack sprayers. Sasaki et al. (2014) indirectly measured the physical effort to work with knapsack hand sprayers (cardiac frequency and $\mathrm{O}_{2}$ consumption), classifying this activity as "moderately heavy".

According to Freitas (2006) knapsack sprayer work requires the operator to constantly move the left upper limb (arm) when it activates the tank pressure lever, moving the upper right limb, directing the nozzle by means of the boom sprayer and a constant walk with the sprayer being carried on his back. When it is called the left or right upper limb, the right becomes the predominant member and the left is the non-predominant member, thus characterizing right or left-handed people. These requirements call into question two important aspects: the effort required by a knapsack sprayer operator on the repetitive movement of the arm which activates the pumping lever, and the consequence of this to the operator during the execution of the work. According to the author repetitive effort can develop muscular fatigue, a fact that has not been researched for knapsack sprayers. The knowledge of this characteristic has also led to the development of alternative equipment based on the

\footnotetext{
${ }^{2}$ Universidade Federal de Pelotas/ Pelotas - RS, Brasil.

Received in: 4-7-2017

Accepted in: 1-17-2018
} 
knapsack hand sprayer using the tractor as a power source (França et al., 2015).

There is little information that provides parameters of maximum effort applied in upper limbs, particularly the shoulder, arm and forearm of a worker. However, Phadke et al. (1992) evaluated the ergonomic conditions of a knapsack sprayer operator. The authors themselves claim to be pioneers in this study; for the tests were considered four models of knapsack sprayers. The results obtained were: average effort to lower the pumping lever of $71.40 \mathrm{~N}$ and to raise, an average effort of $18.70 \mathrm{~N}$, not distinguishing the right arm from the left; number of strokes required to create $300 \mathrm{kPa}$ pressure was 10.15 and the number of strokes required to maintain the $300 \mathrm{kPa}$ pressure was 11.05 , mean values.

No other relevant materials were found, as mentioned, most of them are ergonomic analyzes of different operations, but it can also be mentioned the Consolidation of Labor Laws (CLT - Brazilian Law $n^{\circ}$. 6.514 de 22.12.1977), in its Chapter V, Section XIV, article 198, which establishes as being $60 \mathrm{~kg}$ the maximum weight that an employee can remove individually. However, Bill of law No. 5,746-C modified this law in 2003 , setting this value at $30 \mathrm{~kg}$. Therefore for only one arm it is arbitrated that it is the half of $15 \mathrm{~kg}$ or $147.1 \mathrm{~N}$. The NR-17 in its item 17.2 (Regulatory Standard No. 17 of the Ministry of Labor of Brazil) which describes about the overview, transport and individual discharge of materials, there is no reference to maximum weights. The most indicated value was the NASA-STD-3000B (Man-Systems Integration Standards (MSIS)), which reports that the maximum effort (at worst) of an operator with the arm at $60^{\circ}$ (Figure 1a) is $53.6 \mathrm{~N}$ for the left arm in ascending motion (Figure 1d) and $60.8 \mathrm{~N}$ in descending motion (Figure 1e). For the right arm, the maximum effort is 71.2 $\mathrm{N}$, both for the ascending movement (Figure 1d) and descending (Figure 1e). The NASA-STD-3000B also reveals that tests on young men, 80\% (5th percentile group) with ample working space, $95 \%$ of these can lift weights at the following heights: $180 \mathrm{~N}$ at a height of 1.5 $\mathrm{m}, 280 \mathrm{~N}$ at a height of $0.9 \mathrm{~m}, 590 \mathrm{~N}$ at a height of $0.6 \mathrm{~m}$ and $680 \mathrm{~N}$ at a height of $0.3 \mathrm{~m}$.

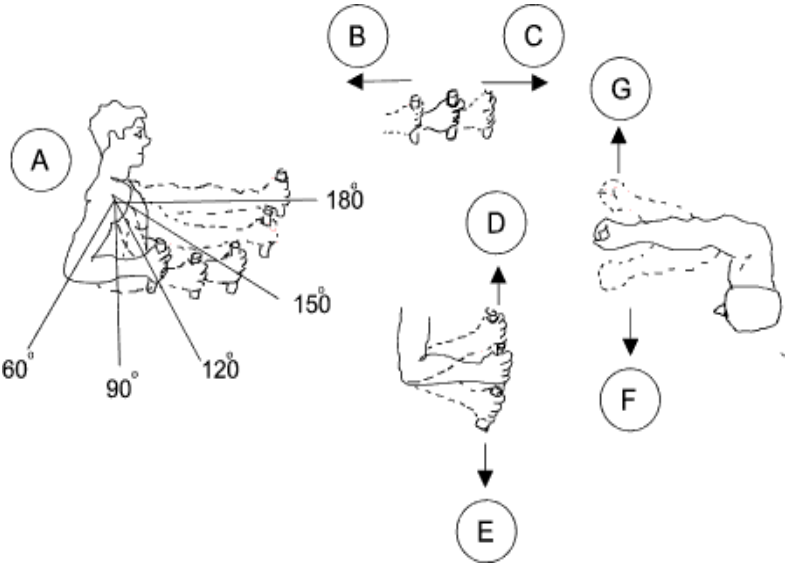

FIGURE 1. Stress positions for upper limbs.

Source:

http://www.roy mech.co.uk/Useful_Tables/Human/Human_streng th.html.

Therefore, this study has the objective of presenting a methodology to measure the effort to which the operator is subjected in the activation of the knapsack sprayers pumping lever verifying if these machines fit within the limitations foreseen by the Brazilian laws and international regulations.

\section{MATERIAL AND METHODS}

The study was carried out in the facilities of the Nucleus of Innovation in Agricultural Machinery and Equipment (NIMEq) at Federal University of Pelotas (UFPEL).

In order to carry out the tests, six models of sprayers were selected for being the most offered in the agricultural equipment trade and in virtual stores of the national market. For the evaluation, the equipment were randomly labeled $\mathrm{A}, \mathrm{B}, \mathrm{C}, \mathrm{D}, \mathrm{E}$ and $\mathrm{F}$, to evaluate their conformity with respect to the requirements, test methods and minimum performance prescribed by the standard ISO 19932-1:2013.The sprayers studied were from brand Guarany, model: SE-20, Brudden, model: S-20, Macrotop, model: MPM-200, Eccofer, model: Eccofer 201 and Jacto, models: PJH 201 and XP 201, but will not be identified in the results. Out of these, two do not have option of inversion activation on the right or left side.

The sprayers were individually adapted to a test rig (Figure 2a).In this, the sprayer pumping lever is activated by a device made by a crank rod system type Scotch Yoke Mechanism $^{\circledR}$ (Figure 2b), which transforms uniform circular motion into alternating linear motion, provided by a "V" mobile roller mechanism (Figure 2c). 

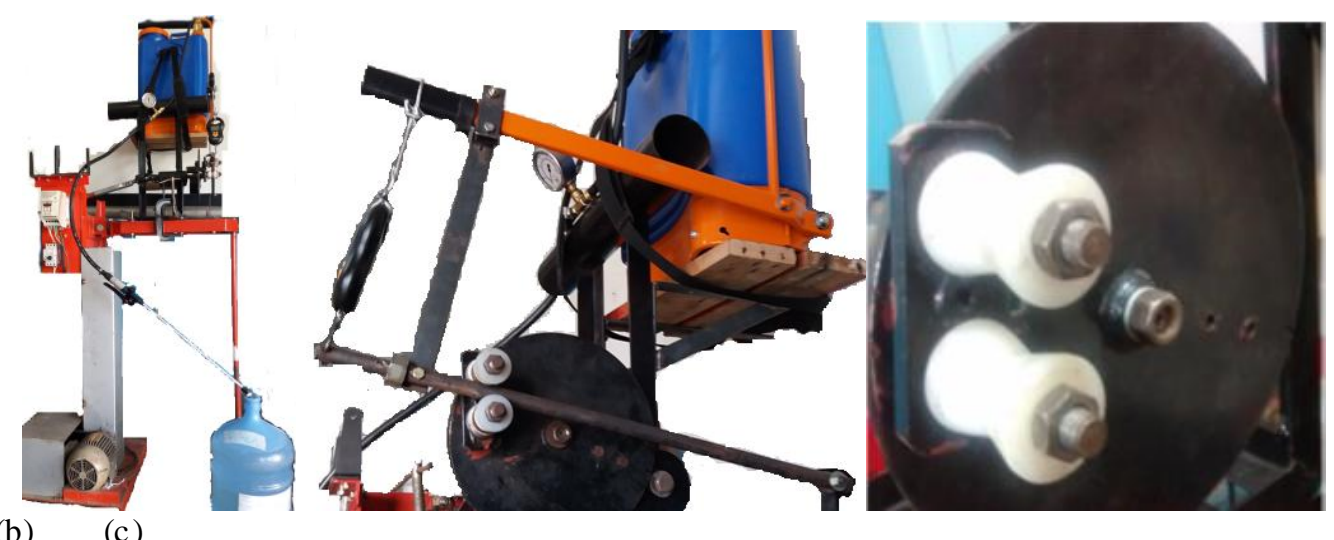

(a)

(b)

(c)

FIGURE 2. Test Rig (a), crank rod system type Scotch Yoke Mechanism ${ }^{\circledR}$ (b) and "V” mobile roller mechanis m (c).

In order to measure the effort exerted on the pumping lever (activation arm) of each sprayer, two pumping lever system was constructed in parallel, according to Figure 3a, where a dynamometer, commercially known as Digital Scale Hook WeiHeng, model 128, resolution of $0.010 \mathrm{kgf}$, capacity of $40 \mathrm{kgf}$ (Figure $3 b$ ) which allowed the verification of the values on the applied efforts in different positions of the movement on the sprayers pumping levers. For data recording regarding to the reading of different applied loads in the different positions of the pumping lever, we used a digital camera, Oly mpus brand, model VR 320.

(a)

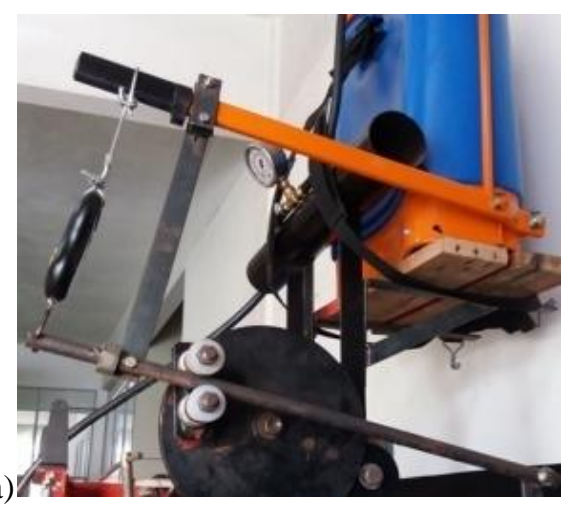

(b)

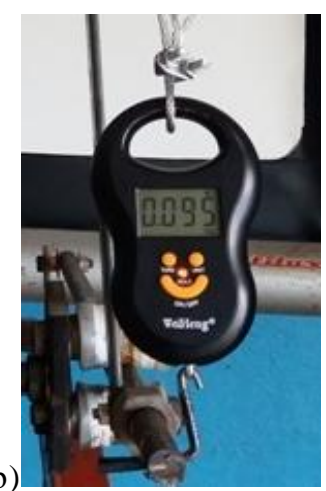

FIGURE 3.Pumping lever system for transferring the applied efforts on the sprayers pumping levers (a) and digital scale to measure the efforts (b).

The lower pumping lever activation occurred by means of the crank rod mechanism. The dynamometer was fixed between the two levers by means of cables, obtaining measurements of the activation efforts when the upper lever of the sprayer was moved downwards by means of the activation mechanism, simulating the activation movement of the operator.

The mechanism developed made it possible to perform the movements of the sprayer pumping lever with the necessary amplitude for each model, allowing adjustment to the different course and length measures of the pumping levers, according to the constructive model of each of the tested equipment.

The activation speed was adjusted digitally by means of a frequency inverter, WEG brand, model CFW 08, which allowed the variation of the rotation between zero (0.00) and $999.9 \mathrm{rpm}$, thus allowing the control of the pump activation number per minute, that is, the number of the lever activations. The frequency of $650 \mathrm{~Hz}$ was used in this equipment providing rotation of $21 \mathrm{rpm}$, thus allowing the sprayers to reach the required working pressure, which was stabilized at $300 \mathrm{kPa}$, according to the standard ISO 19932-1: 2013. The pressure was controlled by a COMAM pressure gauge with a scale from0 to $2.06 \mathrm{MPa}$. The spray tip used was Magno 11001-AD brand, made of ceramic and anti-drift type spray jet for all tests. This was chosen for being commonly sold with the equipment in question and working with the established standard pressure in the $300 \mathrm{kPa}$.

The readings of different applied loads in the different positions of the activation lever were filmed, allowing the data collection to be stored in a spreadsheet for later analysis. First we tested the empty sprayers and later with water working with pressure of $300 \mathrm{kPa}$, being measured finally the loads necessary to return the pumping lever to the superior position.

An analysis of variance (ANOVA) was performed using the Tukey test at the $5 \%$ probability level and Shapiro-Wilk (W) test for the three studied conditions (return before reaching $300 \mathrm{kPa}$ and after reach the pressure of $300 \mathrm{kPa}$ ), considering six levels for spray models (A, B, C, D, E and F).When the treatment data did not present significant normal distribution $(p<0.05)$ it performed a logarithmic transformation of the data. The sprayer was analyzed empty and with water fluid in order to obtain homogeneity for the measurement of applied efforts to the sprayer pumping levers. The average effort and number of activations (cycles) were analyzed to achieve a pressure of $300 \mathrm{kPa}$. When this pressure was reached, the effort was measured for a period of 30 seconds with the trigger triggered, as prescribed in the 
standard ISO 19932-1: 2013. Sprayer model was considered as treatment and number of cycles as repetitions in each test. The performed tests were: average return effort required to the operator, the effort and the quantities of cycles required reaching the $300 \mathrm{kPa}$ pressure and the required cycles and amounts of cycles after reaching the pressure of $300 \mathrm{kPa}$ to check pressure maintenance during work. The response variables were number of cycles, average activation effort $(\mathrm{N})$, maximu m activation effort (N) and time (s) in each cycle (displacement of the pumping lever from top to bottom and its return to top).

\section{RESULTS AND DISCUSS ION}

The normality test after the $300 \mathrm{kPa}$ pressure showed normal distribution by the Shapiro-Wilk test (W) and significant $(\mathrm{p}<0.05)$. However, the observation of the scatter chart for the means of return efforts (Figure 4) shows an asymmetry for the means of the determined efforts with CV lower than 22\% (Table 1). Mean values of the return efforts, and to reach pressure of $300 \mathrm{kPa}$ did not present a significant normal distribution $(\mathrm{p}<0.05)$. With the logarithmic transformation of the data it was observed that they adjusted satisfactorily to the normal and significant distribution $(\mathrm{p}>0.5)$.

TABLE 1. Average return effort required by sprayer operator when supplied with water.

\begin{tabular}{lcccccc}
\hline Sprayer & A & B & C & D & E & F \\
\hline Average (N) & $14.35 \mathrm{a}$ & $14.10 \mathrm{ab}$ & $7.11 \mathrm{~d}$ & $3.80 \mathrm{e}$ & $12.19 \mathrm{c}$ & $1112.52 \mathrm{bc}$ \\
Maximu m (N) & 17.46 & 15.89 & 9.32 & 4.81 & 13.04 & 1114.12 \\
$\sigma(\mathrm{N})$ & 2.06 & 1.57 & 1.57 & 0.59 & 0.78 & 0.88 \\
CV $(\%)$ & 0.14 & 0.11 & 0.22 & 0.16 & 0.07 & 0.07 \\
\hline
\end{tabular}

The averages followed by the same letter do not differ from each other at a significance level of $5 \%$.

When testing with the empty sprayers it was not possible to reach the working pressure of $300 \mathrm{kPa}$, this is due to the decrease in air volume inside the sprayer tank and the inability of the activation pump to be able to compress the air until reach the pressure of $300 \mathrm{kPa}$.

By analyzing the return efforts in the activation when water was used in the sprayer tank (Table 1 and Figure 4) it was verified that sprayer " $D$ " was the one with the lowest value in this operation, being significantly different from the others. The average value obtained with this sprayer was $3.82 \mathrm{~N}$ with maximum of $4.81 \mathrm{~N}$. Sprayers "A" and "B" were the ones that provided the highest mean values of the activation effort, at the rate of 14.32 $\mathrm{N}$ and $14.10 \mathrm{~N}$, respectively, almost four times greater than the value obtained with "D" sprayer, not having differed significantly from each other. The "E" and "F" sprayers did not differ from each other, in relation to the average activation effort presenting the second highest value, which were $12.19 \mathrm{~N}$ and $12.52 \mathrm{~N}$, respectively. On the other hand, the " $C$ " sprayer differed from the others with a mean activation effort of $7.11 \mathrm{~N}$, practically twice as great as the effort obtained with the "D" sprayer, which was the lowest.

The results demonstrate that the maximum upward effort required by the sprayer pumping lever was $17.46 \mathrm{~N}$ (sprayer A). Comparing the result with the value obtained by Phadke et al. (1992) which was $18.70 \mathrm{~N}$ it verified that the results are very close, characterizing agreement of results. This fact can be attributed to the technology of the liquid pumping, which was practically unchanged in these machines in the considered period. The CLT - Law no. 6,514 predicts as limit $147.1 \mathrm{~N}$ for the upper limbs, considering only one of the limbs. Yet the NASA-STD$3000 \mathrm{~B}$ limits to $53.6 \mathrm{~N}$. Therefore, the maximum return effort of the pumping lever is below the limits foreseen by CLT and NASA.

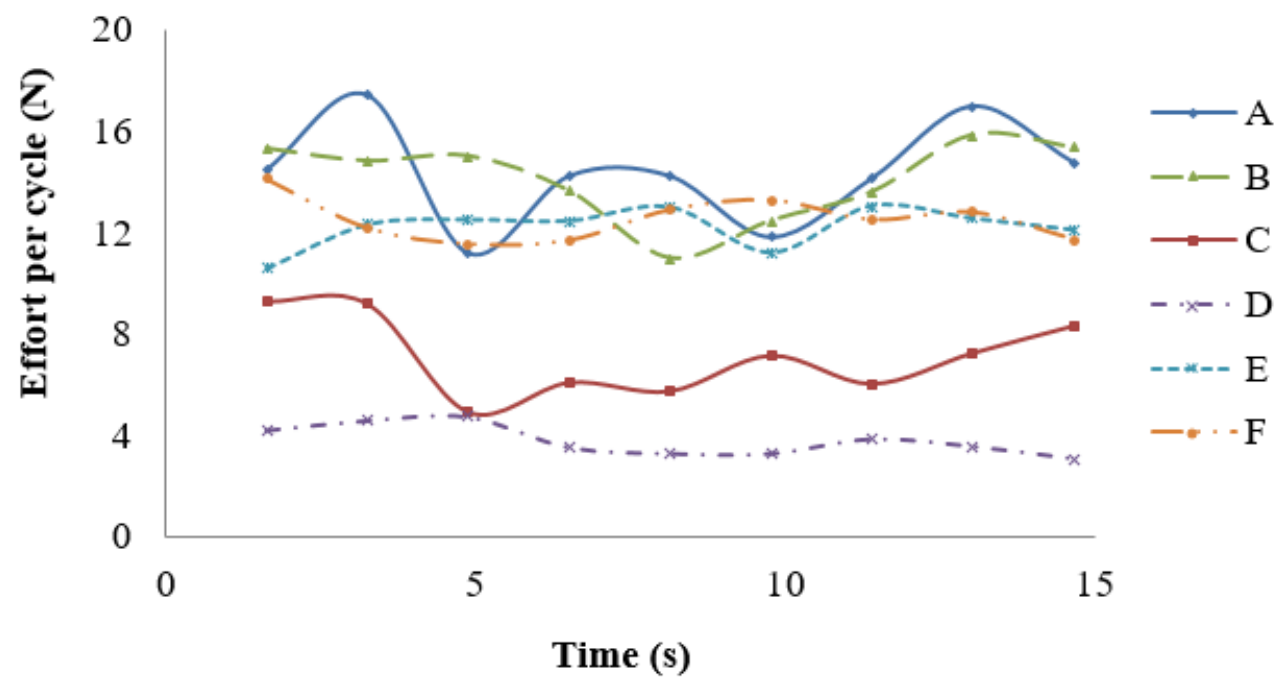

FIGURE 4. Dispersion graphs of the return effort on the sprayer pumping lever tested with water. 
When analyzing the activation effort required reaching $300 \mathrm{kPa}$ pressure for the water fluid (Table 2), the "E" sprayer provided the lowest average effort, with a value of $10.10 \mathrm{~N}$. However, it required 15 cycles to reach this pressure which was due to the fact that for this sprayer there was a need for increasing activation efforts at each cycle. Sprayer "A" was the one that provided the least number of activations ( 8 cycles) to reach the pressure of $300 \mathrm{kPa}$, demonstrating that it has a higher pressure capacity per cycle when compared to the others. Among the tested models it can be considered as the most efficient, although it requires higher activation effort $(37.76 \mathrm{~N})$. This can be caused by greater use of the work due to, for example, a more perfect fit between the cylinder and the piston, or higher cylinder volume. Sprayers "C", "D", "E" and "F" did not differ in relation to the average activation effort, presenting the lowest values which were $19.81 \mathrm{~N} ; 24.61 \mathrm{~N} ; 10.10 \mathrm{~N}$ and $22.65 \mathrm{~N}$; respectively. Sprayer "B" differed from "C", "E" and "F" with an average activation effort of $38.05 \mathrm{~N}$, almost four times greater than the effort obtained with the "E" sprayer, which was the smallest.

The results demonstrate that the maximum (downward) effort required by the sprayer pumping lever was 69.3 N (Sprayer D). Considering the CLT - Law no. 6,514 , the activation effort required to achieve the $300 \mathrm{kPa}$ pressure was below the proposed limits. However, compared to that recommended by NASA-STD-3000B, the effort is above the limit of $60.8 \mathrm{~N}$ for the left arm, but within the limit for the right arm of $71.2 \mathrm{~N}$ in descending movement which is the predominant arm of the operators.

TABLE 2. Results of the efforts and amounts of cycles required to achieve a pressure of $300 \mathrm{kPa}$ with water.

\begin{tabular}{|c|c|c|c|c|c|c|}
\hline Sprayer & $\mathrm{A}$ & $\mathrm{B}$ & $\mathrm{C}$ & $\mathrm{D}$ & $\mathrm{E}$ & $\mathrm{F}$ \\
\hline Average $(\mathrm{N})$ & $37.76 \mathrm{ab}$ & $38.05 a$ & $19.81 \mathrm{bc}$ & 24.61abc & $10.10 \mathrm{c}$ & $22.65 b c$ \\
\hline Number of Cycles & 8 & 14 & 14 & 15 & 15 & 19 \\
\hline Maximu m (N) & 47.07 & 67.67 & 53.25 & 69.33 & 34.91 & 54.13 \\
\hline$\sigma(\mathrm{N})$ & 8.92 & 9.61 & 16.28 & 22.75 & 10.40 & 14.22 \\
\hline $\mathrm{CV}(\%)$ & 0.24 & 0.25 & 0.82 & 0.92 & 1.03 & 0.63 \\
\hline
\end{tabular}

The averages followed by the same letter do not differ from each other at a significance level of $5 \%$.

Analyzing the effort after reach300 kPa pressure for the water fluid (Table 3) it was verified that the "A" sprayer required a lower average effort and a lower maximum effort which were respectively $26.73 \mathrm{~N}$ and $34.72 \mathrm{~N}$. In this way, it can be affirmed that the "A" sprayer becomes, among the analyzed equipment, the one which provides greater comfort to the operator. The sprayers "B", "C" and "F" did not differ in relation to the average activation effort, presenting intermediate values which were $54.19 \mathrm{~N} ; 65.24 \mathrm{~N}$ and $59.27 \mathrm{~N}$, respectively. On the other hand, the " $D$ " sprayer differed from the others with average value activation effort of $88.89 \mathrm{~N}$, more than three times the obtained effort with the "A" sprayer which was the lowest $(26.73 \mathrm{~N})$. Finally, sprayer "E" $(46.45 \mathrm{~N})$ also differed significantly fro $m$ the others.

The results demonstrate that the maximum effort required by the sprayer pumping lever was $108.56 \mathrm{~N}$ (Sprayer D). Considering the CLT - Law no. 6,514, the activation effort required to achieve the $300 \mathrm{kPa}$ pressure was below the proposed limits. However, according to NASA-STD-3000B, the effort is above the limit of $60.8 \mathrm{~N}$ for the left arm with downward movement.

TABLE 3. Results of pumping lever activation efforts after reaching $300 \mathrm{kPa}$ pressure with water.

\begin{tabular}{lcccccc}
\hline Sprayer & A & B & C & D & E & F \\
\hline Average (N) & $26.73 \mathrm{e}$ & $54.19 \mathrm{c}$ & $65.24 \mathrm{~b}$ & $88.89 \mathrm{a}$ & $46.45 \mathrm{~d}$ & $59.27 \mathrm{bc}$ \\
Number of Cycles & 11 & 11 & 11 & 11 & 11 & 11 \\
Maximu m (N) & 34.72 & 61.98 & 73.35 & 108.56 & 54.13 & 64.92 \\
$\sigma(\mathrm{N})$ & 3.43 & 6.86 & 5.98 & 11.57 & 5.39 & 4.31 \\
$\mathrm{CV}(\%)$ & 0.13 & 0.13 & 0.09 & 0.13 & 0.12 & 0.07 \\
\hline
\end{tabular}

The averages followed by the same letter do not differ from each other at a significance level of $5 \%$.

The data of the activation efforts measured in the sprayers with water are shown in the scatter chart, shown in Figure 5. It is noted that the " $\mathrm{A}$ " sprayer, in addition to requiring lower values, also provides decreasing activation effort over time, while the others require increasing activation efforts. 


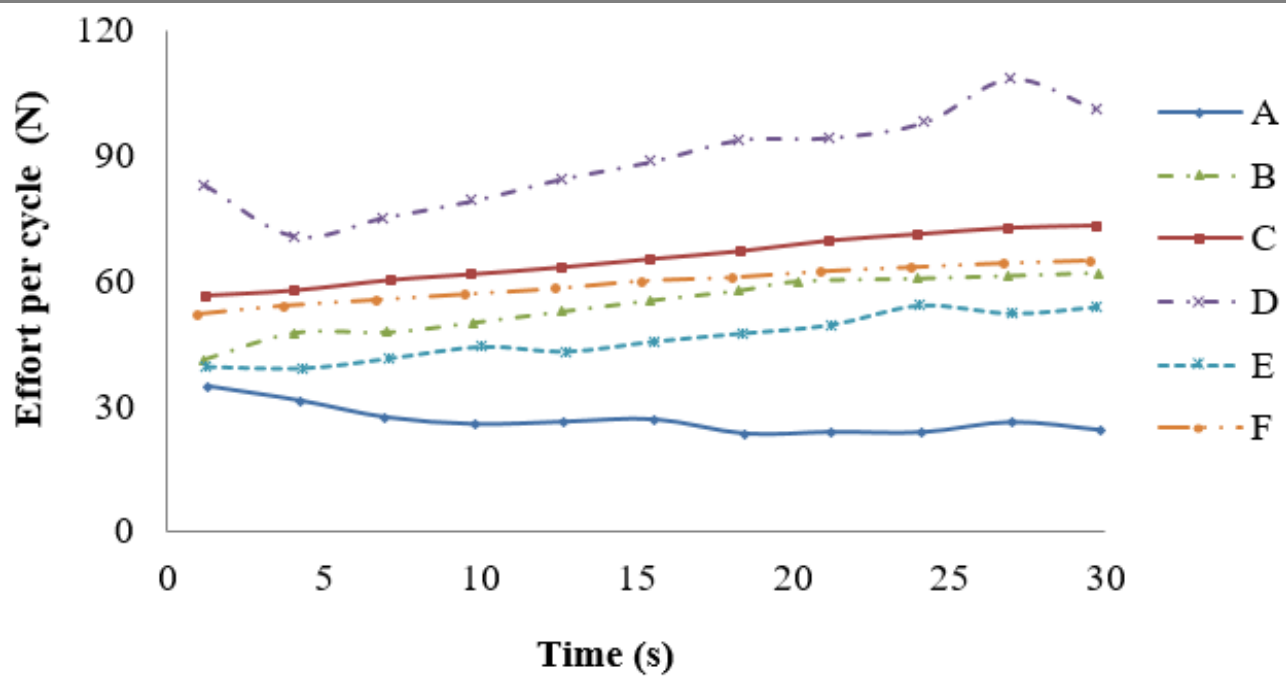

FIGURE 5. Scatter chart of the efforts of the sprayer pumping lever tested with water.

In general, the results demonstrate that the " $\mathrm{A}$ " Sprayer required more effort for the return activation $(17.46 \mathrm{~N})$. The " $\mathrm{D}$ " sprayer required a higher activation effort for both before and after reaching the pressure at 300 $\mathrm{kPa}$, being $69.33 \mathrm{~N}, 108.56 \mathrm{~N}$, respectively. The "E" Sprayer was the least intense in relation to the average activation effort to obtain the pressure of $300 \mathrm{kPa}(10.10$ $\mathrm{N})$. The "A" Sprayer was the most regular and least intense in relation to the average activation effort to maintain the pressure of $300 \mathrm{kPa}(26.73 \mathrm{~N})$, besides requiring a smaller amount of activation cycles of the pumping lever to reach the work pressure.

Although we obtained only one bibliographical reference that could make the comparisons of the results and despite of this reference being very old, it was observed that the results were very similar to those found by Phadke et al. (1992).Therefore, the application of the proposed methodology proved to be efficient, easy and of low cost, so that further studies could be done to provide data for the analysis of the ergonomic working conditions of sprayers and other manual activation lever.

\section{CONCLUS IONS}

The employed methodology was adequate to measure the operator's upward and downward effort required for the operation of knapsack hand sprayers. Considering the Brazilian laws, CLT - Law no. 6,514, all sprayers obtained satisfactory results, i.e. with effort values below the expected limit. However, only "A" and "E" sprayers obtained satisfactory results for the international indications (NASA-STD-3000B) for manual activation lever.

\section{REFERENCES}

França JAL, Gonçalves WS, Romeiro BP, Benett CGS, Silva AR (2015) Desenvolvimento e avaliação de u m pulverizador hidráu lico de barras ríg idas horizontais de baixo custo. Revista de Agricultura Neotropical 2(1):1723.
Freitas CS (2006) Análise ergonômica da atividade com pulverizador costal manual na cultura do café no município de Caratinga. Dis sertação Mestrado, Centro Universitário de Caratinga.

Lopes ES, Oliveira FM, Rodrigues CK (2011)

Determinação da carga física de trabalho na atividade manual de herbicida. A mbiência 7(2):329-337.

Mamidi VR, Ghanshyam C, Kumar PM, Kapur P (2013) Electrostatic hand pressure knapsack spray system with enhanced performance for s mall scale farms. Journal of Electrostatics 71(4):785-790. DOI: https ://doi.org/10.1016/j.elstat.2013.01.011

Phadke SM, Adhaoo SH, Gite LP, Pandya AC, Patel SL (1992) Test code and procedure for ergonomic evaluation of lever-operated knapsack sprayers. International Journal of Industrial Ergono mics 10(4):293-300. DOI: https://doi.org/10.1016/0169-8141(92)90096-I

Sasaki RS, Furtado Júnior MR, Leite ES, Sou za AP, Teixeira MM, Fernandes HC (2014) Avaliação ergonômica de pulverizadores costais utilizados no setor florestal. Revista Árvore 38(2):331-337.

Silva JA, Carolino L, Gimenez LB (2015) Análise e avaliação da tecnologia de aplicação de defensivo agrícola na cultura da lichia. Revista Científica Eletrônica de Agronomia.27. Available in:

http://faef.revista.inf.br/site/e/agronomia-27-edicao-junhode-2015.ht ml\#tab1156. Accessed: Dec 26, 2016.

Souza NSS, Santana VS (2011) Incidência cu mulativa anual de doenças musculoesqueléticas incapacitantes relacionadas ao trabalho em u ma área u rbana do Brasil. Caderno de Saúde Pública 27(11). DOI: http://dx.doi.org/10.1590/S0102-311X2011001100006 